Technological University Dublin

\title{
A Comprehensive Review on Pre-treatment Strategy for Lignocellulosic Food Industry Waste: Challenges and Opportunities
}

\author{
Amit Jaiswal \\ Technological University Dublin, amit.jaiswal@tudublin.ie \\ Rajeev Ravindran \\ Technological University Dublin, r.rajeeviitg@gmail.com
}

Follow this and additional works at: https://arrow.tudublin.ie/schfsehart

\section{Recommended Citation}

Ravindran, R., Jaiswal, A.K., (2015)A Comprehensive Review on Pre-treatment Strategy for Lignocellulosic Food Industry Waste: Challenges and Opportunities, Bioresource Technology (2015), doi: http://dx.doi.org/10.1016/j.biortech.2015.07.106

This Article is brought to you for free and open access by the School of Food Science and Environmental Health at ARROW@TU Dublin. It has been accepted for inclusion in Articles by an authorized administrator of ARROW@TU

Dublin. For more information, please contact

arrow.admin@tudublin.ie, aisling.coyne@tudublin.ie, gerard.connolly@tudublin.ie.

Funder: Technological University Dublin (DIT)

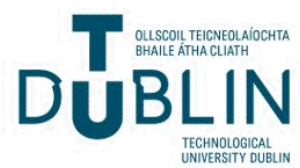




\section{Accepted Manuscript}

Review

A Comprehensive Review on Pre-treatment Strategy for Lignocellulosic Food Industry Waste: Challenges and Opportunities

Rajeev Ravindran, Amit Kumar Jaiswal

PII:

S0960-8524(15)01077-9

DOI: http://dx.doi.org/10.1016/j.biortech.2015.07.106

Reference: BITE 15339

To appear in:

Bioresource Technology

Received Date:

30 June 2015

Revised Date:

29 July 2015

Accepted Date:

30 July 2015

Please cite this article as: Ravindran, R., Jaiswal, A.K., A Comprehensive Review on Pre-treatment Strategy for Lignocellulosic Food Industry Waste: Challenges and Opportunities, Bioresource Technology (2015), doi: http:// dx.doi.org/10.1016/j.biortech.2015.07.106

This is a PDF file of an unedited manuscript that has been accepted for publication. As a service to our customers we are providing this early version of the manuscript. The manuscript will undergo copyediting, typesetting, and review of the resulting proof before it is published in its final form. Please note that during the production process errors may be discovered which could affect the content, and all legal disclaimers that apply to the journal pertain. 


\title{
A Comprehensive Review on Pre-treatment Strategy for Lignocellulosic Food Industry Waste: Challenges and Opportunities
}

\author{
Rajeev Ravindran and Amit Kumar Jaiswal*
}

School of Food Science and Environmental Health, College of Sciences and Health, Dublin Institute of Technology, CathalBrugha Street, Dublin, Republic of Ireland.

*Corresponding author:

Email: amit.jaiswal@dit.ie; akjaiswal@outlook.com

Tel: +35314024547

\section{Abstract}

Lignocellulose is a generic term used to describe plant biomass. It is the most abundant renewable carbon resource in the world and is mainly composed of lignin, cellulose and hemicelluloses. Most of the food and food processing industry waste are lignocellulosic in nature with a global estimate of up to 1.3 billion tons/year. Lignocellulose, on hydrolysis, releases reducing sugars which is used for the production of bioethanol, biogas, organic acids, enzymes and biosorbents. However, structural conformation, high lignin content and crystalline cellulose hinder its use for value addition. Pre-treatment strategies facilitate the exposure of more cellulose and hemicelluloses for enzymatic hydrolysis. The present article confers about the structure of lignocellulose and how it influences enzymatic degradation emphasizing the need for pre-treatments along with a comprehensive analysis and categorization of the same.

Finally, this article concludes with a detailed discussion on microbial/enzymatic inhibitors that arise post pre-treatment and strategies to eliminate them.

Keywords: Lignocellulose; food industry waste; pre-treatment; enzyme inhibitors; renewable resources 


\section{Introduction}

Lignocellulose is one of the most abundant yet underutilised bio-resource in the world. It is considered among the best source of cheap carbohydrates and applied as a potential substrate for the production of a range of high value products including biofuels such as bioethanol and biogas. Apart from its abundance and easy availability, the fact that $75 \%$ of its composition is contributed by polysaccharide makes it a fiercely sought out raw material for the biofuel production (Sun \& Cheng, 2002). Besides biofuels lignocellulose can be used as primal matter for the production of other value added products such as enzymes.

In 2010, an article was published in the Ethanol Producer magazine entitled 'The economics of enzyme production' according to which the cost of producing cellulosic bioethanol is majorly dependent upon to the cost of enzymes used in the process. Although, this scenario has improved, there are still a few worries regarding harnessing the cost of production of bioethanol to becoming economically feasible. One such problem that needs to be addressed immediately is the carbohydrate source used for enzyme production. Theoretically, it is possible to recycle cheap carbohydrate sources from industries and use it as a sugar source for enzyme production. However, the heterogeneous nature of biomass carbohydrate sources hinders them to be efficient nutrients leading to incompetent growth of the enzyme producing microorganisms. This is due to the fact that 5-C and 6-C sugars are absorbed by the microbe at different rates during fermentation (Abdel-Rahman et al., 2015). Furthermore these carbohydrate sources comprises of other substances that may act as inhibitors for microbial growth, and leads to poor fermentation yields and subsequently raising the production costs for the desired products.

An efficient technique to remove components that inhibit microbial growth and enzymatic degradation of lignocellulose is a potential solution to increase its utility. With this aim, several studies have been dedicated to devising various pre-treatment methods with differing nature. The lignocellulosic substance undergoes a single or a sequential pre-treatment before its efficacy as a carbon source is evaluated. 


\section{Lignocellulosic food industry waste}

The food processing industry in the EU is progressing at a very fast pace. According to the report published by FoodDrinkEurope the European food and drink industry is the largest manufacturing sector in the continent, and had a turnover of $€ 1,048$ billion in 2012 which was a 3.1\% increase from 2011. Such a growing trend in the industry can give rise to more waste that is eventually left untreated due to lack of feasible options. Land filling remains the cheapest option for waste management by industries. Other options include incineration, which requires a lot of energy and, composting, a process that is quite slow. Improper treatment of these waste leads to their putrefaction giving rise to toxic gases such as methane and leaching of other toxic liquids proving hazardous to the environment. Most of the waste generated from the food industry is lignocellulosic in nature, and thus can be potential substrates for the production of high value products. Products that can be produced from food and industry waste include fossil fuel alternatives such as ethanol, butanol, biogas, and fuel oil, food supplements such as prebiotics and bioactive compounds, volatile fatty acids and enzymes that are of commercial importance (Uçkun Kiran et al., 2014; Yin et al., 2014).

The European Commission has coined a new term, 'Bioeconomy' which focuses on addressing the environmental challenges that the world faces today. An article published by the European Commission in 2009 states that EU produces an estimated 138 million tons of bio-waste from industries every year of which $40 \%$ is being used as landfill. The motivation behind bioeconomy is to reduce relying on natural resources by transforming the manufacturing sector. This can be achieved by promoting sustainable production of renewable resources from land, fisheries and aquaculture and their conversion into food, feed, fibre, bio-based products and bio-energy, while generating more jobs and giving rise to new industries (Commission, 2009).

\section{Structure of Lignocellulose}

Lignocellulose is made of lignin and carbohydrates like cellulose, hemicellulose, pectin, ash, salts and minerals. Cellulose is a polysaccharide that is made up of $D$-glucose bonded to each by $\beta(1 \rightarrow 4)$ linkage forming linear chains. Cellulose is mainly found in the cell wall of plant biomass. The plant cell wall is composed of microfibrils that are formed by cellulose chains bound together by hydrogen bonds. Microfibrils are insoluble long-chained compounds made up of 36 glucan chains held together by hydrogen bonds and each chain contains about 5,000 to 14,000 glucose molecules. Cellulose can exist in different polymorphs that are crystalline in nature. Natural cellulose is found in a polymorph structure called polymorph I. Three other polymorphs of cellulose have been attained via different pre-treatments viz. polymorphs II, III and IV. Cellulose also exists in amorphous form which is soluble and can be easily digested by enzymes (Kulasinski, Keten, Churakov, Derome, \& Carmeliet, 2014).

Hemicellulose is a heterogeneous polymer made up of short chains of polysaccharide molecules. They constitute $15-35 \%$ of the plant biomass and are composed of five different sugar monomers viz. Dxylose, L-arabinose (pentoses), D-galactose, D-mannose and D-glucose (hexoses). They are usually found in the form of O-acetyl-4-O-methylglucuronoxylans and O-acetylgalactoglucomannans depending upon the source of biomass. Uronic acids, like $\alpha$-D-glucuronic, $\alpha$-D-4-O-methylgalacturonic and $\alpha$-Dgalacturonic acids have also been found in hemicellulose. Other sugars such as $\alpha$-I-rhamnose and $\alpha-I-$ 
fucose may also be existent in small quantities. Hemicelluloses are linked to cellulose by hydrogen bonds and to lignin by covalent bonds (Sun et al., 2014).

Lignin is the most abundant constituent in plant biomass. It has an aromatic and amorphous nature and its structure varies according to the plant species it is derived from. Lignin monomers are basically phenylpropane units that differ only in the substitution of methoxyl groups on the aromatic rings. The three main monolignols (lignin monomers) that form the lignin polymer are p-hydroxyphenyl alcohol $(H)$, coniferyl alcohol (G), and synapyl alcohol (S). Softwoods usually contain more of the H subunit as compared to $\mathrm{G}$ and $\mathrm{S}$ where as in grass varieties all the monolignols are found in equal proportions (Duval \& Lawoko, 2014).

One of the most important limiting factors for making lignocellulose susceptible to microbial attack is the lignin content. Research has shown that the removal of lignin facilitates cellulose hydrolysis. The mechanism by which lignin obstructs hydrolysis of cellulose is still not completely understood. However, two reasons have been proposed that may be the lead to this phenomenon. Firstly, lignin is a structural polysaccharide which imparts strength to the plant cell wall by covalently linking to hemicellulose (Yuan et al., 2013). The covalent bonding between lignin and cellulose prevents the carbohydrate to be exposed for enzymatic hydrolysis. Secondly, woody biomass is harder to treat as compared to grass biomass. A comparison of lignin structures in both substrates reveal that the extent of cross-linking and the phenyl content lignin found in wood is far more complex than that of grassy substrates (Ververis et al., 2004).

Another property of lignin which is detrimental for cellulose activity is its capacity to irreversibly adsorb enzymes. A study on the adsorption kinetics of enzyme to lignin and the effect of temperature revealed that higher temperatures accelerated the adsorption process attaining equilibrium. This may be a problem when conducting enzymatic hydrolysis at higher temperatures. The addition of surfactants was seen to reduce the adsorption of cellulase to lignin (Tu et al., 2009). Certain pre-treatments have been observed to be more effective against lignin-enzyme adsorption as compared to others. Kumar et al. (2013) reported that ammonia fibre expansion pre-treatment was superior over $\mathrm{SO}_{2}$ and acid-pretreatment in terms of cellulase adsorption capacity.

Pectin is a naturally occurring hydrocolloid found in the plant cell wall. They are majorly composed of homogalacturonan (HG), (a polymer of 1-4 linked a-D-galacturonic acid which is methylated) with rhamnogalacturonan (RG) I and II, xylogalacturonan, arabinan and arabinogalactan regions as minor constituents. Pectin can be classified as high methoxyl pectin and low methoxyl pectin depending upon the degree of esterification with ethanol (Espitia et al., 2014). Pectin is a commercially important compound and used widely in the food industry as a gelling, thickening or stabilising agent. Reports on the same biomass substance may show varying results due to a variety of reasons, including methods of analysis undertaken, source of biomass, pre-treatments employed, and the time of harvest can affect the chemical composition of lignocellulose. It is therefore advised that reported literature should simply be taken as guidelines to analyse substrate composition independently. 


\section{Pre-treatment of lignocellulose}

The utilisation of cellulose in biomass as a carbon source via enzymatic hydrolysis is a complicated process. It involves the adsorption of enzymes on the substrate surface, the synergistic effects of other protein components on hydrolysis, and the release of hydrolysed product in to the bulk liquid. A lot of factors influence this process and they can be broadly categorised in to structural features of lignocellulose and the mechanisms and interactions related to enzyme kinetics. Nonetheless, addressing the factors related to structure of lignocellulose holds the key to efficient hydrolysis of substrate. The aspects that influence the difficulty in the degradation of biomass residues include lignin content, hemicellulose, available amorphous cellulose as compared to its crystalline counter-part, the degree of polymerisation, acetyl groups, plant protein-enzyme interaction, the association of cellulose with hemicellulose and lignin, the accessible surface area to enzymatic degradation and porosity and the residual surface area of biomass (Singh et al., 2015).

Pre-treatments are necessary practises to address these issues by bringing in structural and compositional changes in lignocellulose. This is achieved by exerting high pressure or temperature or a combination of both, treatment with corrosive chemicals such as acids and alkali or the usage of molecular disruption techniques such as ultrasound and plasma etc. Pre-treatments can remove lignin and hemicellulose to a certain extent and increase the porosity and concentration of amorphous cellulose. Novel pre-treatments for lignocellulose have been devised by several researchers over the past three decades and will be discussed in later section. Table 1 refers to a comparison of various lignocellulosic waste materials and the common pre-treatments applied for them.

\section{Factors influencing the choice of pre-treatment}

There are a number of factors that need to be considered while employing a pre-treatment strategy for a particular biomass residue before it is used as a substrate for the fermentation. These factors include low capital and energy investments, overall effectiveness and applicability over a wide variety of substrates. Subjecting the lignocellulosic biomass to pre-treatment should not render the sample unusable for further use. Added advantages, such as the ability to retrieve the hemicellulose content in the aqueous solution, are desired. Most importantly, pre-treatments should lower the capital cost, the operational cost and the biomass cost. Besides all these factors, there are a few parameters that should be taken in consideration when pre-treatments are chosen for lignocellulose. These parameters depend upon the physical and chemical features of the biomass that help or resist enzymatic hydrolysis. A detailed description of how these features affect lignocellulose degradation is given in the following section. The best pre-treatment result in end products which support the growth of desired microbes, not result in unemployable substrate molecules and also not give rise to inhibitory substances that hinder the growth or prove to be harmful to producers.

\subsection{Crystallinity of lignocellulose}

Crystalline cellulose exists in different polymorphs and is seen in microfibrils in plant cell wall. They are formed by long chains of $(1,4) \beta$-D glucan bonded together by hydrogen bonds. The presence of 
hydrogen bonds between chains resists enzymatic and microbial attack while breaking them enhance depolymerisation (Chundawat et al., 2010). Studies have shown that during hydrolysis digestion of amorphous cellulose takes place before crystalline cellulose. The crystallinity of cellulose can be measured by the different X-ray diffraction methods. The crystallinity index is used to measure the degree of crystallinity in biomass and pulps and is determined by the equation:

$$
\text { Crystallinity index }(\mathrm{CRI})(\%)=\frac{\left(I_{002}-I_{a m}\right) \times 100}{I_{002}}
$$

$I_{002}$ is the intensity of diffraction of 002 peak at $2 \vartheta \approx 22.5^{\circ}$ and $I_{a m}$ is the scattering intensity of amorphous region $\left(2 \vartheta \approx 18.7^{\circ}\right.$ ) (Bansal et al. (2010).

\subsection{Degree of polymerisation}

Degree of polymerisation of cellulose is an important parameter in determining biomass recalcitrance. Pre-treatment of lignocellulose as well as enzymatic hydrolysis is a depolymerisation process of cellulose (Meng \& Ragauskas, 2014). Size exclusion chromatography (SEC) studies can reveal the degree of polymerisation of a particular substrate sample. Melander and Vuorinen (2001) conducted a study to determine the depolymerisation of carboxymethyl cellulose after enzymatic digestion using SEC. They detected the separated $\mathrm{CMC}$ hydrolysates as total carbon content and reducing sugars. The degree of depolymerisation was determined by dividing the number of anhydroglucose units by the reducing sugar concentration. Several studies have been focused on the efficacy of pre-treatments on the depolymerisation of cellulose. Steam explosion treatment of cotton stalks enhanced the saccharification of the substrate by reducing the degree of polymerization of cellulose (Huang et al., 2015).

\subsection{Accessible surface area}

The process of hydrolysis of cellulose greatly depends upon the adsorption of enzyme on to the substrate. This is determined by the accessible surface area making it a limiting factor for efficient enzymatic digestion. The accessible surface area is in turn dependent upon particle size, porosity and pore volume. The measurement of surface area of substrate can be carried out by Brunauer-EmmettTeller method (Chen et al., 2011). According to this method increase in surface area in sugar cane bagasse can be achieved by using dilute $\mathrm{H}_{2} \mathrm{SO}_{4}$ assisted by microwave heating. Variations in the pore size distribution can be determined by using differential scanning colorimetry. In general, measure of porosity of the substrate is considered as direct indication of the accessible surface area. Ye and Berson (2014) reported an enhanced rate of cellulose hydrolysis on increase in substrate binding surface area. 


\subsection{Acetyl groups}

Acetyl groups form the backbone of hemicellulose structures in plant cell wall. Studies have shown that the presence of acetyl group can hinder the effective digestion of cellulose. The degree of acylation has been reported to be a crucial factor in cellulose hydrolysis (Jiang et al., 2014). Liquid hot water pretreatment has found to be effective in removing the acetyl groups found in hemicellulose and converting them in to acetic acid (Jiang et al., 2015). The acetyl groups may inhibit enzyme activity by interfering in the hydrogen bond formation between cellulose and cellulose binding domains. The negative effects of acetyl group inhibition can be eliminated by saponification (Balat et al., 2008).

\section{Pre-treatment techniques}

The aim of pre-treatments is to facilitate or increase the efficacy of lignocellulose hydrolysis by improving accessibility towards cellulose-rich fractions. This is achieved by the removal of lignin and hemicellulose, factors which affect the availability of cellulose for microbial degradation. It also focuses on the purging other factors that have been detailed in an earlier section of this article. The past three decades have witnessed a tremendous amount of research being done in the area of pre-treatments. Different techniques have been employed to investigate the efficiency as a pre-treatment measure. The synergistic effects on effective lignin removal have also been explored on a wide scale. Pre-treatment techniques can be classified in various ways. Depending on the $\mathrm{pH}$ that is maintained during the process pre-treatments can be grouped in to three: acidic, neutral and alkaline (Singh et al., 2015). A comprehensive classification of pre-treatments involves the assembly of different techniques based on their mode of action. Accordingly, pre-treatment methods can be broadly categorised in to physical, chemical, physico-chemical and biological. As the name implies physico-chemical pre-treatments involves a combination of physical or biological methods with chemical strategies. Figure 1 depicts a classification of various pre-treatments methods for lignocellulose suggested by the authors after extensive literature review.

\subsection{Physical pre-treatment}

\subsubsection{Grinding and milling}

Grinding is a size reduction technique used for biomass pre-treatment that increases the reactivity and does not release any effluents. The size of the sample is preliminarily reduced by cutting and milling. Ultra-fine powder is collected by the use of a sieve. The choice of sieve depends upon the final particle size reduction that is aimed to be achieved. The effects of grinding include alterations in the degree of polymerisation, porosity, surface area and crystallinity. The final particle size mainly depends upon the conditions and intensity of grinding. Silva et al. (2012) achieved progressive particle size reduction by employing sieve based grindings, ball milling and jet milling. The enzymatic degradability of the substrate was 
improved by this process. Zakaria et al. (2015) used wet disk milling as a secondary pretreatment step to extract sugars from recalcitrant oil palm mesocarp fibre. They found that wet disk milling increased the surface area accessible for the conversion of cellulose to glucose.

\subsubsection{Ultrasonic pre-treatment}

Ultrasonic pre-treatment employs ultrasonic radiation to breakdown the complex network of polymerisation in biomass. Cavitation produced due to the pulsating high frequency ultrasonic waves penetrates in to polysaccharides and disrupts the mesh of cross linking polymers facilitating better enzymatic degradation. The biomass suspension is irradiated for 10 minutes with ultrasonic radiation at $20 \mathrm{kHz}$ and $200 \mathrm{KW}$ before enzymatic treatment. Nakayama and Imai (2013) reported the increase in adsorption of cellulase when the authors used ultrasonic pre-treated Kenaf leaves for enzymatic hydrolysis. Employing pre-treatment designed by augmenting ionic liquids and ultra-sonication of rice straw. Ultrasonic pre-treatment assisted with $\mathrm{FeCL}_{3}$ was found to improve the acid hydrolysis of cellulose thereby enhancing the crystallinity (Li et al., 2015).

\subsubsection{Centrifugal grinding}

As the name suggests, centrifugal grinding a modified grinding mechanism which utilises an advanced grinder. This technique results in size reduction of biomass to increase contact surface area and reduce cellulose crystallinity leading to better exposure of polymers for hydrolysis. Centrifugal grinding is superior over ordinary grinding in such a way that it exerts multiple effects viz. impact and shear. Centrifugal grinding, done in successive steps, result in the reduction of particle to a great degree. In a particularly interesting study, Silva and Xavier (2011) examined the chemical composition of fractions obtained after passing grinded wheat straw through sieves of different sizes. They found out that larger fractions were mostly made up of cellulose while the smaller fractions had protein and ash in them.

\subsubsection{Extrusion pre-treatment}

Extrusion is a process where uniformly moistened biomass material is passed through a screw assembly and applied pressure upon under high temperature at a particular frequency. It requires a device called the extruder; the biomass can be mixed with different chemicals like sodium hydroxide, urea or thiourea to increase the severity of the pre-treatment process. Lamsal et al. (2010) reported in higher reducing sugar yields using extrusion pre-treatment as opposed to grinding using wheat bran as substrate.

Parameters, such as screw speed, barrel temperature and their collaboration has a substantial impact on sugar recovery from biomass. A comparative study between three pre-treatment strategies viz. dilute acid, alkali and extrusion was conducted using soybean hulls as the lignocellulosic substrate. It was found that post pre-treatment the glucose yield after enzymatic hydrolysis compared with untreated substrate increased by 69.6\%, $128.7 \%$ and $132.2 \%$, respectively (Yoo et al., 2011). 


\subsection{Chemical pre-treatment}

\subsubsection{Dilute-acid pre-treatment}

Dilute acid pre-treatment hydrolyses hemicellulose and makes cellulose more susceptible to enzymatic degradation. Strong acids, like sulphuric acid, in diluted form are used to treat the lignocellulosic biomass. The biomass samples are immersed in dilute acids and the temperature is raised to $160^{\circ} \mathrm{C}$ and maintained for 10 minutes. With dilute-acid pre-treatment a considerable reduction in galactosyl and xylosyl groups (hemicellulose) can be achieved however, with a higher lignin content (Zhou et al., 2014). Jatropha curcas shells were used to study the effect of dilute sulphuric acid pre-treatment on hydrolysis. Almost $70 \%$ of enzymatic conversion of cellulose was obtained after following this pre-treatment protocol (Martín et al., 2015).

\subsubsection{Acid-acetone pre-treatment}

Acid-acetone pre-treatment takes advantage of acidolysis at high temperatures followed by cold shock. A quantified amount of biomass is mixed with concentrated phosphoric acid (not less than $85 \%$ ) and kept in a rotary air-bath for $1 \mathrm{~h}$ at $120 \mathrm{rpm}$ and $50^{\circ} \mathrm{C}$. The slurry is then mixed with pre-cold acetone and mixed thoroughly. After centrifuging the slurry for 10 minutes at $8000 \mathrm{rpm}$ the supernatant is collected for reducing sugar analysis while solids are washed again thrice in distilled water and then used for enzymatic hydrolysis. Studies have shown that over $99 \%$ of the total cellulose content in acid-acetone pre-treated lignocellulose was available for enzymatic hydrolysis to obtain glucose (Qin, Wu, Zheng, Dong, \& Yang, 2014).

\subsubsection{Pre-treatment using ionic liquids}

Ionic liquids are thermally stable organic solvents that are capable of polar and non-polar organic, inorganic and polymeric compounds. They have low volatility, are non-flammable and can be recycled. This can be considered an advantage considering how cost intensive pre-treatments can be. Pretreatments using ionic liquids do not require much energy as well. Some of the ionic liquids that are used for treating lignocellulose are an anionic chloride, formate, acetate or alkylophosphonate; moieties that can form strong hydrogen bonds with cellulose and other carbohydrates. Pre-treatment using ILs involves mixing it with the biomass at a ratio of $20: 1$ and then heating it for $120^{\circ} \mathrm{C}$ for 30 minutes. Deionised water is then added in to the mixture to form a ratio of 5:1. The IL/water mixture is then separated from the biomass by vacuum filtration. In a study involving energy cane bagasse, $7.9 \%$ or lignin removal was achieved using IL pre-treatment. The insufficient removal of lignin was attributed to its location in the lignin-carbohydrate complex (Qiu et al., 2012).

\subsubsection{Alkaline potassium permanganate pre-treatment}

This pre-treatment takes advantage of the strong oxidation property of potassium permanganate. Potassium permanganate is generally considered safe as compared to ozone and ionic liquids. Alkaline 
potassium permanganate solution (APP) has the ability to delignify biomass by oxidation with high carbohydrate retention. This is done by breaking the ester and ether bonds between lignin and carbohydrates. Corn bobs were used in a study employing APP pre-treatment as the lignin removal strategy. Researchers were able to find that the optimum time of exposure for maximum lignin removal was 6 hours. Also, it was observed that higher temperatures favoured the pre-treatment process (Ma et al., 2015).

\subsubsection{Organosolv pre-treatment}

Organosolv pre-treatment is normally performed by using strong inorganic acid catalyst like sulphuric acid which hydrolyses the bonds in lignin. The advantage of this process is the option to recover lignin as a value added product. Additionally, solvent recovery requires minimal energy. Amiri et al. (2014) reported the use of aqueous ethanol containing $1 \% \mathrm{w} / \mathrm{w}$ of sulphuric acid for pre-treating rice straw with a solid-liquid ratio of $1: 8$. The temperature of the mixture was maintained at $150-180^{\circ} \mathrm{C}$ for $30-60$ minutes. After cooling it in an ice bath, the pre-treated material was finally washed with $60 \%$ ethanol and kept to dry overnight. The treatment of the biomass for 1 hour at $180^{\circ} \mathrm{C}$ resulted in $60 \%$ removal besides the partial dissolution of hemicellulose in the organic liquor. Developments in this mode of pretreatments involve the use of other chemicals such as formaline, acetolinesulphric acid catalysed ethanol and auto-catalysed ethanol. Figure 2 depicts the enzymatic conversion of glucan into glucose from organosolv treated wheat straw (Chen et al., 2015).

\subsubsection{Pre-treatment using metal chlorides}

This method requires a high pressure reactor to perform the pre-treatment. Biomass is loaded in the reactor along with metal chlorides $\left(\mathrm{FeCl}_{3}, \mathrm{FeCl}_{2}, \mathrm{CrCl}_{3}, \mathrm{ZnCl}_{2}\right.$, and $\left.\mathrm{AlCl}_{3}\right)$. The reactants are heated to $170^{\circ} \mathrm{C}$ for 30 minutes. The pre-treated solids are removed via filtration. A study conducted by Chen et al. (2014) revealed that using metal chlorides for pre-treatment of lignocellulose results in the decrease in the total mass of the substrate. Most of the carbohydrate gets degraded in the acid environment and a major share of it appeared in the effluent. The hydrolysis of bamboo biomass by dilute hydrochloric acid in ionic liquid involving metal ions such as $\mathrm{Na}^{+}, \mathrm{K}^{+}, \mathrm{Mg}^{2+}, \mathrm{Ca}^{2+}, \mathrm{Cu}^{2+}$ and $\mathrm{Fe}^{3+}$ was conducted to study the effects. A maximum sugar yield of $67.1 \%$ was obtained at $100^{\circ} \mathrm{C}$ and $\mathrm{Cu}^{2+}$ was found to be the best metal ion for this process (Wang et al., 2014).

\subsubsection{Plasma pre-treatment}

This pre-treatment technique employs plasma to make changes on the surface of cellulose. Plasma treatment results in extirpation resulting in the increase in coarseness of cellulose. Plasma generated high reactive species such as $\mathrm{HO}^{\circ}$ and $\mathrm{H}_{2} \mathrm{O}_{2}$ which degraded cellulose to obtain glucose. A study was conducted to find out the changes on the surface of cellulose when exposed to dielectric barrier discharge plasma. AFM and XPS were the analytical tools for investigating the surface bound changes. According to the data obtained from AFM, the corresponding changes can influence the adhesion of molecules (preferably protein and enzyme) on the substrate surface (Flynn et al., 2013). Experiments 
involving plasma pre-treated biomass for bioethanol production resulted in a maximum ethanol yield of 52\% (Schultz-Jensen et al., 2011).

\subsection{Physico-chemical pre-treatment}

\subsubsection{Steam explosion}

Steam assisted fractionation of biomass materials (also called autohydrolysis) is one of the oldest and yet the most effective pre-treatment methods that facilitate enzymatic hydrolysis. The process involves subjecting the biomass to high pressure and temperature for a certain amount of time after which the sample is rapidly decompressed resulting in the breakdown of the lignin-carbohydrate complex. However, a drawback that has been reported with this method is that with woody substrates the extent of delignification is very less leading to lesser enzymatic hydrolysis of cellulose (Kumar et al., 2012). A study using corn fibre as substrate employed steam explosion as the pre-treatment strategy with $6 \% \mathrm{SO}_{2}$ at $190^{\circ} \mathrm{C}$. Accordingly, sequential $\mathrm{SO}_{2}$ combined steam explosion followed by enzymatic hydrolysis resulted in a high polysaccharide conversion of $81 \%$ (Vivekanand, Olsen, Eijsink, \& Horn, 2014). Sequential pre-treatment using steam explosion and $1 \% \mathrm{H}_{2} \mathrm{SO}_{4}$ was found to assist enzymatic digestibility of cotton stalks and also resulted in high sugar-ethanol yield (Huang et al., 2015).

\subsubsection{Hot water pre-treatment}

Hot water pre-treatment is ideal for lignocellulose substrates where the addition of chemicals for delignification can result in loss of useful biomass. This method does not require corrosion resistant reactors or chemicals and the formation of toxic compounds is almost absent (Jiang et al., 2015). The process is performed in a customized high pressure reactor. $100 \mathrm{~g}$ of dried substrate is loaded in to the reactor along with a $900 \mathrm{ml}$ of deionised water and $2 \mathrm{~g}$ of $\mathrm{NaOH}$. The stirring speed is maintained at 600 $\mathrm{rpm}$ with a temperature of $230^{\circ} \mathrm{C}$. After pre-treatment the reactor is cooled in cold, running water and as the temperature lowers to $80^{\circ} \mathrm{C}$ the slurry is separated in solid and liquid fractions using vacuum filtration (Li et al., 2014).

\subsubsection{Wet oxidation}

Wet oxidation technique relies on the high pressure and temperature in aqueous conditions for the breakdown on lignocellulose. It employs oxidative agents and results in the formation of hydroxyl radicals which corrode in to lignin and carbohydrates. Experiments are conducted in a loop reactor with the over-head chamber filled with 12 bars of oxygen gas. After the reaction the solids are separated from the liquid by vacuum filtration. Wet oxidation has been reported as a safe pre-treatment method as no harmful compounds result from it. Using clover and rye grass as substrate, a team of researchers were able to attain an enzymatic hydrolysis conversion efficiency of $93.6 \%$. Furthermore, the overall glucose yield post-pre-treatment and hydrolysis was found to be $75.5 \%$ (Martín et al., 2008). 


\subsubsection{Ammonia fibre expansion}

Ammonia fiber expansion (AFEX) is one of the most successfully tested lignocellulose pre-treatment methods for the production of fermentable sugars from biomass. Anhydrous or highly concentrated ammonia is added (ammonia loading) to wet substrate (water loading) at moderate temperatures and high pressure conditions. This condition is maintained for a while (residence time) before the pressure is released. This leads to the vaporisation of ammonia which can be collected, recycled and used again. AFEX pre-treatment is most suitable for preventing cellulase adsorption to lignin. A comparative study of AFEX pre-treatment on corn stover pre-soaked in hydrogen peroxide and normal substrate showed that using the former, the enzymatic digestibility was enhanced with values of $87.78 \%$ and $90.64 \%$ for glucan and xylose respectively (Zhao et al., 2014).

\subsubsection{Super critical $\mathrm{CO}_{2}$ explosion}

Super critical carbon dioxide $\left(\mathrm{SCCO}_{2}\right)$ is a modified steam explosion involving $\mathrm{CO}_{2}$ instead of atmospheric air. A specified amount of biomass is wetted and loaded in a reactor after which the pressure within the reactor is built up by means of super critical $\mathrm{CO}_{2}$. This condition is maintained for some time following which the pressure in the reactor is suddenly realised resulting in fractionation of the lignocellulosic substrate (Srinivasan \& Ju, 2012). Super critical $\mathrm{CO}_{2}$ diffuses in to the crystalline structure of cellulose and the explosion created subsequently disrupts the biomass cell wall and facilitates easy access to cellulytic enzymes towards the substrate. A maximum glucose yield of $30 \%$ was obtained from corn stover samples after $\mathrm{SCCO}_{2}$ pre-treatment and consequent hydrolysis (Narayanaswamy et al., 2011).

\subsubsection{Integrated hydroxyl radicals and hot water pre-treatment (IHRWT)}

IHRWT pre-treatment is a combination of hot water treatment and pre-treatment using hydroxyl radicals. Hydroxyl radicals have the capability to break hydrogen bonds in carbohydrates and lignin. In a study conducted by (Gao et al., 2015) hydroxyl radicals were generated in vivo by the Fenton or HaberWiess reaction by mixing $\mathrm{H}_{2} \mathrm{O}_{2}$ and $\mathrm{FeSO}_{4}$ at concentrations of $0.0 .18 \%$ and $11.9 \mathrm{mM}$ respectively. The biomass was initially exposed to hot water pre-treatment $\left(100^{\circ} \mathrm{C}, 30\right.$ minutes) which deteriorated the complex polymeric structures in lignocellulose to expose lignin and polysaccharides. As a result a glucose yield of $59.9 \mathrm{mg} / \mathrm{g}$ DM was obtained with a cellulose conversion rate of $88.1 \%$ on enzymatic hydrolysis.

\subsection{Biological pre-treatment}

Biological pre-treatment systems rely on biological agents to delignify lignocellulose and make the process of enzymatic hydrolysis more convenient. Unlike physical and chemical pre-treatment methods, biological pre-treatments do not involve high temperature and/or pressure and does not require acids, alkali or any reactive species. Additionally, the process does not generate any undesirable products. However, the disadvantage of using biological pre-treatment strategies is that there is limited control over the whole process. Moreover, it is a slow process and thus time consuming. Nonetheless, one may employ these pre-treatment techniques for lesser capital costs and environmental benefits. Biological 
pre-treatment procedures may broadly be classified in to use of microbial consortium, fungal treatments and enzymatic treatments.

\subsubsection{Microbial consortium}

The idea of using mixed cultures for lignocellulose processing spawns from the fact that using a single species for lignin removal does not concur with the same process occurring in nature; lignocellulosic material is degraded as a cooperative effort of many microbial species regardless of the aerobic/anaerobic conditions. Employing a microbial consortium for delignification eliminates several drawbacks encountered in a single species treatment such as metabolite repression and feedback regulation (Zhang et al., 2011). Meanwhile, ensilage is a conventional technology used for the storage of animal feed. Naturally occurring bacteria produces enzymes that digest the lignocellulosic material providing substrates that is more easily digested by ruminant animals. Lactobacillaceae appears as the dominant species in the consortium of microbes that ferment biomass during ensilation. Although, the capability to degrade lignin is virtually absent, the effects on the biomass made by the microbial consortium improve the yield of fermentable sugars derived from the substrate (Chen et al., 2007). For this reason, ensilage storage cannot be counted upon as a stand-alone pre-treatment process.

\subsubsection{Pre-treatments using fungal species}

Delignification of biomass using fungal species is an area that has witnessed a lot of research in recent years. 'White rot fungi' is a small group of basidiomycetic fungus that thrive on wood. They are capable of breaking down and demineralizing lignin. They do this with the help of one of their two enzyme systems viz. the oxidative lignolytic system which attacks the phenyl rings in lignin and the hydrolytic enzyme system degrades cellulose and hemicellulose to release fermentable sugars. The oxidative lignolytic system comprises of three major enzymes: lignin peroxide, manganese peroxide and laccase. The most common species of white rot fungi that has been employed for treatment of lignocellulose include Phanerochaetechrysosporium, Phanerochaetecarnosa, Ganodermalucidum, Pleurotusostreatus, Pleurotuspulmonarius, Phanerochaetechrysosporium and Trametes sp (Vicuña, 2000).

Brown rot fungi are another class of lignocellulose degrading fungi that uses enzymes to degrade cellulose and hemicellulose with minimal removal of lignin. It has been theorized that the removal of lignin by brown rot fungus follows a non-enzymatic pathway using hydroxyl radicals (Jensen et al., 2001). According to research done by Schilling et al. (2009) delignification is step undertaken by brown rot fungi as a pre-treatment of sorts: to facilitate saccharification. In another study conducted by Schilling et al. (2012) using different types of wood, the saccharification rates after pre-treatment increased three folds by using brown rot fungi (specifically Gloeophyllumtrabeum and Postia placenta).

\subsubsection{Enzymatic pre-treatment}

While fungal pre-treatment methods directly use white rot fungi to remove lignin from biomass, enzymatic pre-treatment procedures employ pure enzymes derived from the same organisms to achieve 
a common goal. Laccase, manganese peroxide and versatile peroxide are enzymes that are used extensively to treat the lignocellulosic substrate. Laccases are phenoloxidases containing multiple copper ions and they catalyze the oxidation of phenols, anilines and aromatic thiols. Phenol removal by laccase enhances microbial growth, improves fermentation capability and reduces the time the organism spends in lag phase (Oliva-Taravilla et al., 2015). Manganese peroxidase is another enzyme produced by white rot fungi which takes advantage of the manganese in woody substrates. It is generally thought that the inability of brown rot fungi to produce this enzyme have compelled it depend on hydroxyl radicals and Fenton reaction to degrade lignin. Manganese peroxidase contains a heme component with a catalytic cycle and it is uniquely selective for $\mathrm{Mn}^{2+}$ ions for oxidation. The oxidation of $\mathrm{Mn}^{2+}$ to $\mathrm{Mn}^{3+}$ is coupled by the reduction of hydrogen peroxide to water. $\mathrm{Mn}^{3+}$ is a highly reactive species capable of interactions with phenols, non-phenolic aromatic compounds and long chain unsaturated fatty acids leading to bond cleavage in lignin (Brown \& Chang, 2014).

\section{Other relevant pre-treatments}

\subsubsection{Thermal expansion pre-treatment}

Thermal expansionary pre-treatment is a two-step process involving boiling of biomass at high pressure followed by rapid decompression. A process temperature ranges from $170-200^{\circ} \mathrm{C}$ is applied for a residence of 0-60 minutes. Torrefaction is kind of thermal pre-treatment which involved temperatures in the range of $200-300^{\circ} \mathrm{C}$. Torrefaction can be categorised as wet and dry depending upon the presence and absence of water. Wet torrefaction involves hot compressed water at temperatures of $200-260^{\circ} \mathrm{C}$ in a pressure reactor. Dry torrefaction, also known as low temperature pyrolysis were the biomass is exposed to an environment with an inert gas such as nitrogen at temperatures ranging from 200 to $300^{\circ} \mathrm{C}$. A study conducted to compare the effect of both torrefaction effects on the equilibrium moisture content of biomass revealed that pre-treated biomass is more hydrophobic than raw biomass (Acharjee et al., 2011).

\subsubsection{Microwave pre-treatment}

Microwave pre-treatment is a modified version of thermal pre-treatment. As opposed to thermal pretreatment, heat is provided to the biomass material directly in the form of microwave radiation which converts to thermal energy. The microwaves penetrate the material and heat the entire volume from the inside. The process is rapid and uniform in nature. The advantages of this process are not confined to uniform heating and lower time requirement but increased energy efficiency, controlled heating and excellent control over the whole process. Different microwave-assisted pre-treatments have been tried and tested and found to be very effective. About $46 \%$ of lignin was removed retaining $90 \%$ of glucose and $76 \%$ of hemicellulose when sweet sorghum bagasse was subjected to microwave-assisted dilute ammonia pre-treatment (Chen et al., 2012). 


\section{Formation of inhibitors}

Compounds formed during the pre-treatment process of lignocellulose may prove inhibitory to enzyme activity, microbial growth and metabolism. Potential inhibitory chemicals that can be released from cellulose, hemicellulose and lignin when employing thermochemical treatments are aliphatic acids such as acetic, formic and levulinic acid, furaldehydes such as furfural and 5-hydroxymethylfurfural (HMF) and, uronic acid, 4-hydroxybenzoic acid, vanillic acid, vanillin, phenol, cinnamaldehyde, and formaldehyde. Furan derivatives are formed by the thermal breakdown of pentose and hexose sugars. The two furan derived representatives, 2-furaldehyde (furfural) and hydroxyl methyl furfural arise from the decomposition of pentose and hexose sugars on treating lignocellulose with diluted sulphuric acid. Furan derivatives are detrimental to the activity of several enzymes that are involved in microbial metabolism such as hexokinase, aldolase, phosphofructokinase, triosephosphate dehydrogenase, and alcohol dehydrogenase (Behera et al., 2014).

Aliphatic acids are by-products of thermal augmented acid treatment of sugars. Lignocellulose hydrolysate derived aliphatic acids include acetic acid, formic acid and levulinic acid. Acetic acid is formed by two ways: the acetyl groups in hemicellulose are dissociated during hydrolysis to form acetic acid. Secondly, acetic acid is a by-product of the fermentation process (Taherzadeh et al., 1997). Formic acid is the dissociation product of furfural while HMF is the precursor for levulinic acid formation (Ulbricht et al., 1984). Phenolic compounds are a derivative of lignin degradation when lignocellulose undergoes thermal pre-treatment augmented by acid catalysis (Trajano et al., 2013). Phenolic compounds are also generated by the breakdown of sugars. Several recent research showed that phenolic compounds inhibits the growth of microorganisms; though, the precise process by which phenolic compounds inhibit microbial growth and fermentation process is yet not elucidated convincingly. The measurement of phenolic compounds in the pre-treated lignocellulose can be assessed by performing gas chromatography-mass spectroscopy (GC-MS), high performance liquid chromatography (HPLC) and liquid chromatography coupled with mass spectrometry (Jonsson et al., 2013).

\section{Inhibitory effects on microbial processes}

Enzyme hydrolysis is dependent upon the solid biomass concentration rather than enzyme to cellulose ratio. Studies have shown that the activity of enzyme gradually decreases with the increase in solid biomass concentration even when the enzyme to cellulose ratio is kept constant (Ximenes et al., 2010). Apart from substrate and product inhibition on lignocellulose hydrolysis there are several other inhibitors that take form depending upon the nature of the biomass and the pre-treatment undertaken. Weak acids have the capability to diffuse through the lipoprotein plasma membrane. This changes the nature of the cytosol to acidic. Maintaining a neutral cellular environment is crucial to the sustainability of cells. So, to counter the effect of the acid infusion, cells start excreting protons through the plasma membrane ATPase which eventually leads to lysis and death (Viegas \& Sá-Correia, 1991). Another group of compounds called amphiphilic molecules (also known as uncouplers) causes cell disruption following another mechanism. It dissolves the inner mitochondrial membrane of eukaryotic cells. The mitochondria thus losses its ability to regenerate ATP from ADP, and the cell starves to death. Some of 
the uncouplers found in lignocellulose hydrolysate are $p$-hydroxybenzoic acid and salicylic acid (Verduyn et al., 1992).

Furan derivatives viz. furfural and hydroxymethyl furfural has been known to interfere with the activities of enzymes such as alcohol dehydrogenase, pyruvate dehydrogenase and aldehyde dehydrogenase. The presence of furfural has a negative effect on the growth of Pichia sitipitisunder aerobic condition (Yücel \& Aksu, 2015). It has also been found that furfural can breakdown DNA and hinder the process of RNA and protein synthesis (Palmqvist \& Hahn-Hägerdal, 2000). HMF has not been found to be as toxic as furfural. Nonetheless it shares the similar mechanism of enzyme and microbial inhibition as furfural. Together with furfural it shows synergistic effects which are more harmful than when they are found separately. Like furfural it also can be metabolized by S. cerevisiae (Field et al., 2015).

The mechanism by which phenolic and other aromatic compounds inhibit microbial growth and enzyme activity is yet to be understood comprehensively. However, a study conducted by Ximenes et al. (2010) probed in to the effect of different concentrations of phenolic derivatives found in lignocellulose hydrolysate such as vanillin, syringaldehyde, trans-cinnamic acid, and hydroxybenzoic acid on the activity of $\beta$-glucosidase. They found that while a ratio of $4 \mathrm{~g}$ of vanillin to $1 \mathrm{~g}$ of protein reduces the enzyme activity by $50 \%$, enzymes from Trichodermareesei and Aspergillusniger were comparatively uninhibited (Jonsson et al., 2013).

\section{How to overcome these inhibitors?}

There are several strategies to overcome the effect of inhibitors on the fermentation process. Ideally, there can be four ways to eliminate the ill effects of inhibitors: (1) prevent the formation of inhibitors during pre-treatment and hydrolysis (2) detoxify the hydrolyzate prior to fermentation; (3) develop genetically modified microorganisms that can resist attack of inhibitors (4) conversion of toxic compounds into neutral products. To prevent the formation of toxic compounds, a simple strategy would be the careful choice of lignocellulosic material and the application of mild pre-treatments. This may not agree with the industrial demand as a high cellulose and subsequent sugar yield is desired which can only be obtained by implementing harsh pre-treatment methods. Addition of chemicals to the fermentation process is one way for detoxification. Over liming is one of the most economical options for the removal of inhibitors. Over liming is the utilization of $\mathrm{Ca}(\mathrm{OH})_{2}$ for lignocellulose pre-treatment (Ranatunga et al., 2000). Alriksson et al. (2005) used $\mathrm{NH}_{4} \mathrm{OH}$ as a source of nitrogen as well as a measure against inhibitors. Treatments using $\mathrm{NH}_{4} \mathrm{OH}$ at $\mathrm{pH} 10.0$ resulted in a substantial decrease in furfural and hydroxymethyl furfural concentrations along with an increase in fermentation efficiency. The immobilization of fermentative microbes and enzymes is yet another novel way to resist the detrimental properties of inhibitors (Behera et al., 2014).

Enzymatic treatment has found success in the removal of toxic compounds. Employing laccase and peroxidase enzymes obtained from Trametesversicolor in hemicellulose hydrolysate resulted in the complete removal of phenolic compounds (Jönsson et al., 1998). Microbes can also be employed for the abatement of fermentation inhibitors. Coniochaeta ligniaria NRRL30616 is a fungus that has been identified as a microbe that is capable to metabolize furfural, HMF and phenolic derivatives. A study 
using the efficacy of this fungal organism was conducted by Cao et al. (2013). They found that $C$. ligniariaNRRL30616 was able to convert the toxic molecules either in to biomass or in to less harmful chemicals. One employing this microbe for biological removal of inhibitors, a higher cellulose conversion rate was observed. Physical methods can also be employed for the exclusion of inhibitors. Vacuum evaporation is one of the most common physical methods used to remove inhibitors. It results in the complete removal of volatile fractions such as acetic acid, furfural and vanillin but results in the concentration of no-volatile compounds lignin derivatives. A better method to remove harmful chemicals is through extraction. Kim et al. (2011) conducted a study to find out which component of the lignocellulose hydrolysate was responsible for reducing the enzyme activity. Accordingly, phenolics had a major influence on cellulose degradation and complete removal of the same resulted in regaining of the full enzyme activity. The phenolic compounds can be removed using PEG surfactant, activated charcoal and/or ethyl acetate.

\section{Conclusion}

The concept of valorisation of lignocellulosic food industry waste is an innovative idea which can lead to huge economic gains. With stringent laws on waste disposal and environmental protection, there is huge scope for innovative pre-treatments for food industry-derived lignocellulose. The choice of pretreatment must be made based on the physical and chemical nature of biomass aiming for maximum release of reducing sugars via enzymatic hydrolysis. Also, some pre-treatments give rise to inhibitory molecules which should be prevented or removed upon formation. To conclude, existing pre-treatment strategies must be redesigned to meet the demands of large scale production facilities.

\section{Acknowledgement}

Authors would like to acknowledge the funding from Dublin Institute of Technology (DIT) under the Fiosraigh Scholarship programme, 2014.

\section{Conflict of Interest}

The authors declare no conflict of interest.

\section{References}


Abdel-Rahman, M.A., Xiao, Y., Tashiro, Y., Wang, Y., Zendo, T., Sakai, K., Sonomoto, K. 2015. Fed-batch fermentation for enhanced lactic acid production from glucose/xylose mixture without carbon catabolite repression. J. Biosci. Bioeng. 119(2), 153-158.

Acharjee, T.C., Coronella, C.J., Vasquez, V.R. 2011. Effect of thermal pretreatment on equilibrium moisture content of lignocellulosic biomass. Bioresour. Technol. 102(7), 4849-4854.

Alriksson, B., Horvath, I., Sjöde, A., Nilvebrant, N.-O., Jönsson, L. 2005. Ammonium Hydroxide Detoxification of Spruce Acid Hydrolysates. in: Twenty-Sixth Symposium on Biotechnology for Fuels and Chemicals, (Eds.) B. Davison, B. Evans, M. Finkelstein, J. McMillan, Humana Press, pp. 911-922.

Amiri, H., Karimi, K., Zilouei, H. 2014. Organosolv pretreatment of rice straw for efficient acetone, butanol, and ethanol production. Bioresour. Technol. 152(0), 450-456.

Balat, M., Balat, H., Öz, C. 2008. Progress in bioethanol processing. Prog. EnergCombust. Sci. 34(5), 551-573.

Bansal, P., Hall, M., Realff, M.J., Lee, J.H., Bommarius, A.S. 2010. Multivariate statistical analysis of X-ray data from cellulose: A new method to determine degree of crystallinity and predict hydrolysis rates. Bioresour. Technol. 101(12), 4461-4471.

Behera, S., Arora, R., Nandhagopal, N., Kumar, S. 2014. Importance of chemical pretreatment for bioconversion of lignocellulosic biomass. Renew. Sust. Energ. Rev. 36(0), 91-106.

Brown, M. E., \& Chang, M. C. (2014). Exploring bacterial lignin degradation. Curr. opin. in chem. biol., 19, 1-7.

Cao, G., Ximenes, E., Nichols, N.N., Zhang, L., Ladisch, M. 2013. Biological abatement of cellulase inhibitors. Bioresour. Technol. 146(0), 604-610.

Chen, C., Boldor, D., Aita, G., Walker, M. 2012. Ethanol production from sorghum by a microwave-assisted dilute ammonia pretreatment. Bioresour. Technol. 110(0), 190-197.

Chen, H., Zhao, J., Hu, T., Zhao, X., Liu, D. 2015. A comparison of several organosolv pretreatments for improving the enzymatic hydrolysis of wheat straw: Substrate digestibility, fermentability and structural features. Appl. Energ. 150(0), 224-232.

Chen, L., Chen, R., Fu, S. 2014. Preliminary exploration on pretreatment with metal chlorides and enzymatic hydrolysis of bagasse. Biomass Bioenerg. 71(0), 311-317. 
Chen, W.-H., Tu, Y.-J., Sheen, H.-K. 2011. Disruption of sugarcane bagasse lignocellulosic structure by means of dilute sulfuric acid pretreatment with microwave-assisted heating. Appl. Energ. 88(8), 2726-2734.

Chen, Y., Sharma-Shivappa, R., Chen, C. 2007. Ensiling Agricultural Residues for Bioethanol Production. Appl. Biochem. Biotechnol.143(1), 80-92.

Chundawat, S.P.S., Vismeh, R., Sharma, L.N., Humpula, J.F., da Costa Sousa, L., Chambliss, C.K., Jones, A.D., Balan, V., Dale, B.E. 2010. Multifaceted characterization of cell wall decomposition products formed during ammonia fiber expansion (AFEX) and dilute acid based pretreatments. Bioresour. Technol. 101(21), 8429-8438.

Commission, E. 2009. What is the Bioeconomy?, Vol. 2015.

Duval, A., Lawoko, M. 2014. A review on lignin-based polymeric, micro- and nano-structured materials. React. Funct. Polym. 85(0), 78-96.

Espitia, P.J.P., Du, W.-X., Avena-Bustillos, R.d.J., Soares, N.d.F.F., McHugh, T.H. 2014. Edible films from pectin: Physical-mechanical and antimicrobial properties - A review. Food Hydrocolloid. 35(0), 287-296.

Field, S. J., Ryden, P., Wilson, D., James, S. A., Roberts, I. N., Richardson, D. J., . . Clarke, T. A. (2015). Identification of furfural resistant strains of Saccharomyces cerevisiae and Saccharomyces paradoxus from a collection of environmental and industrial isolates. Biotech. for biof., 8(1), 33.

Flynn, C.N., Byrne, C.P., Meenan, B.J. 2013. Surface modification of cellulose via atmospheric pressure plasma processing in air and ammonia-nitrogen gas. Surf. Coat. Technol. 233(0), 108-118.

Gao, F., Gao, L., Zhang, D., Ye, N., Chen, S., Li, D. 2015. Enhanced hydrolysis of Macrocystis pyrifera by integrated hydroxyl radicals and hot water pretreatment. Bioresour. Technol. 179(0), 490-496.

Huang, Y., Wei, X., Zhou, S., Liu, M., Tu, Y., Li, A., Chen, P., Wang, Y., Zhang, X., Tai, H., Peng, L., Xia, T. 2015. Steam explosion distinctively enhances biomass enzymatic saccharification of cotton stalks by largely reducing cellulose polymerization degree in $\mathrm{G}$. barbadense and G. hirsutum. Bioresour. Technol. 181(0), 224-230. 
Jensen, K.A., Houtman, C.J., Ryan, Z.C., Hammel, K.E. 2001. Pathways for Extracellular Fenton Chemistry in the Brown Rot Basidiomycete Gloeophyllum trabeum. Appl. Environ. Microbiol. 67(6), 2705-2711.

Jiang, W., Chang, S., Li, H., Oleskowicz-Popiel, P., Xu, J. 2015. Liquid hot water pretreatment on different parts of cotton stalk to facilitate ethanol production. Bioresour. Technol. 176(0), 175-180.

Jiang, W., Peng, H., Li, H., Xu, J. 2014. Effect of acetylation/deacetylation on enzymatic hydrolysis of corn stalk. Biomass Bioenerg. 71(0), 294-298.

Jonsson, L., Alriksson, B., Nilvebrant, N.-O. 2013. Bioconversion of lignocellulose: inhibitors and detoxification. Biotechnol. Biofuels. 6(1), 16.

Jönsson, L.J., Palmqvist, E., Nilvebrant, N.O., Hahn-Hägerdal, B. 1998. Detoxification of wood hydrolysates with laccase and peroxidase from the white-rot fungus Trametes versicolor. Appl. Microbiol. Biotechnol. 49(6), 691-697.

Kim, Y., Ximenes, E., Mosier, N.S., Ladisch, M.R. 2011. Soluble inhibitors/deactivators of cellulase enzymes from lignocellulosic biomass. Enzyme Microb. Technol. 48(4-5), 408415.

Kulasinski, K., Keten, S., Churakov, S. V., Derome, D., \& Carmeliet, J. (2014). A comparative molecular dynamics study of crystalline, paracrystalline and amorphous states of cellulose. Cellulose, 21(3), 1103-1116.

Kumar, L., Arantes, V., Chandra, R., Saddler, J. 2012. The lignin present in steam pretreated softwood binds enzymes and limits cellulose accessibility. Bioresour. Technol. 103(1), 201-208.

Kumar, R., Hu, F., Hubbell, C.A., Ragauskas, A.J., Wyman, C.E. 2013. Comparison of laboratory delignification methods, their selectivity, and impacts on physiochemical characteristics of cellulosic biomass. Bioresour. Technol. 130(0), 372-381.

Lamsal, B., Yoo, J., Brijwani, K., Alavi, S. 2010. Extrusion as a thermo-mechanical pretreatment for lignocellulosic ethanol. Biomass Bioenerg. 34(12), 1703-1710.

Li, H.-Q., Jiang, W., Jia, J.-X., Xu, J. 2014. pH pre-corrected liquid hot water pretreatment on corn stover with high hemicellulose recovery and low inhibitors formation. Bioresour. Technol. 153(0), 292-299. 
Li, J., Zhang, X., Zhang, M., Xiu, H., He, H. 2015. Ultrasonic enhance acid hydrolysis selectivity of cellulose with $\mathrm{HCl}-\mathrm{FeCl} 3$ as catalyst. Carbohydr. Polym. 117(0), 917-922.

Ma, L., Cui, Y., Cai, R., Liu, X., Zhang, C., Xiao, D. 2015. Optimization and evaluation of alkaline potassium permanganate pretreatment of corncob. Bioresour. Technol. 180(0), 16.

Martín, C., García, A., Schreiber, A., Puls, J., Saake, B. 2015. Combination of water extraction with dilute-sulphuric acid pretreatment for enhancing the enzymatic hydrolysis of Jatropha curcas shells. Ind. Crop. Prod. 64(0), 233-241.

Martín, C., Thomsen, M.H., Hauggaard-Nielsen, H., BelindaThomsen, A. 2008. Wet oxidation pretreatment, enzymatic hydrolysis and simultaneous saccharification and fermentation of clover-ryegrass mixtures. Bioresour. Technol. 99(18), 8777-8782.

Melander, M., Vuorinen, T. 2001. Determination of the degree of polymerisation of carboxymethyl cellulose by size exclusion chromatography. Carbohydr. Polym. 46(3), 227-233.

Meng, X., Ragauskas, A.J. 2014. Recent advances in understanding the role of cellulose accessibility in enzymatic hydrolysis of lignocellulosic substrates. Curr. Opin. Biotechnol. 27(0), 150-158.

Nakayama, R.-i., Imai, M. 2013. Promising ultrasonic irradiation pretreatment for enzymatic hydrolysis of Kenaf. J. Env. Chem. Eng. 1(4), 1131-1136.

Narayanaswamy, N., Faik, A., Goetz, D.J., Gu, T. 2011. Supercritical carbon dioxide pretreatment of corn stover and switchgrass for lignocellulosic ethanol production. Bioresour. Technol. 102(13), 6995-7000.

Oliva-Taravilla, A., Moreno, A.D., Demuez, M., Ibarra, D., Tomás-Pejó, E., GonzálezFernández, C., Ballesteros, M. 2015. Unraveling the effects of laccase treatment on enzymatic hydrolysis of steam-exploded wheat straw. Bioresour. Technol. 175(0), 209215.

Palmqvist, E., Hahn-Hägerdal, B. 2000. Fermentation of lignocellulosic hydrolysates. II: inhibitors and mechanisms of inhibition. Bioresour. Technol. 74(1), 25-33.

Qin, W., Wu, L., Zheng, Z., Dong, C., \& Yang, Y. (2014). Lignin Hydrolysis and Phosphorylation Mechanism during Phosphoric Acid-Acetone Pretreatment: A DFT Study. Molecules, 19(12), 21335-21349. 
Qiu, Z., Aita, G.M., Walker, M.S. 2012. Effect of ionic liquid pretreatment on the chemical composition, structure and enzymatic hydrolysis of energy cane bagasse. Bioresour. Technol. 117(0), 251-256.

Ranatunga, T.D., Jervis, J., Helm, R.F., McMillan, J.D., Wooley, R.J. 2000. The effect of overliming on the toxicity of dilute acid pretreated lignocellulosics: the role of inorganics, uronic acids and ether-soluble organics. Enzyme Microb. Technol. 27(3-5), 240-247.

Schilling, J., Tewalt, J., Duncan, S. 2009. Synergy between pretreatment lignocellulose modifications and saccharification efficiency in two brown rot fungal systems. Appl. Microbiol. Biotechnol. 84(3), 465-475.

Schilling, J.S., Ai, J., Blanchette, R.A., Duncan, S.M., Filley, T.R., Tschirner, U.W. 2012. Lignocellulose modifications by brown rot fungi and their effects, as pretreatments, on cellulolysis. Bioresour. Technol. 116(0), 147-154.

Schultz-Jensen, N., Kádár, Z., Thomsen, A., Bindsley, H., Leipold, F. 2011. Plasma-assisted pretreatment of wheat straw for ethanol production. Appl. Biochem. Biotechnol. 165(34), 1010-1023.

Silva, G.G.D., Couturier, M., Berrin, J.-G., Buléon, A., Rouau, X. 2012. Effects of grinding processes on enzymatic degradation of wheat straw. Bioresour. Technol. 103(1), 192200.

Silva, G.G.D., Xavier, R.S.G. 2011. Successive centrifugal grinding and sieving of wheat straw. Powder Technol. 208(2), 266-270.

Singh, J., Suhag, M., Dhaka, A. 2015. Augmented digestion of lignocellulose by steam explosion, acid and alkaline pretreatment methods: A review. Carbohydr. Polym. 117(0), 624-631.

Srinivasan, N., Ju, L.-K. 2012. Statistical optimization of operating conditions for supercritical carbon dioxide-based pretreatment of guayule bagasse. Biomass Bioenerg. 47(0), 451458.

Sun, S.-N., Cao, X.-F., Xu, F., Sun, R.-C., Jones, G.L., Baird, M. 2014. Structure and thermal property of alkaline hemicelluloses from steam exploded Phyllostachys pubescens. Carbohydr. Polym. 101(0), 1191-1197. 
Sun, Y., Cheng, J. 2002. Hydrolysis of lignocellulosic materials for ethanol production: a review. Bioresour. Technol. 83(1), 1-11.

Taherzadeh, M.J., Niklasson, C., Lidén, G. 1997. Acetic acid-friend or foe in anaerobic batch conversion of glucose to ethanol by Saccharomyces cerevisiae? Chem. Eng. Sci. 52(15), 2653-2659.

Trajano, H., Engle, N., Foston, M., Ragauskas, A., Tschaplinski, T., Wyman, C. 2013. The fate of lignin during hydrothermal pretreatment. Biotechnol. Biofuels. 6(1), 110.

Tu, M., Pan, X., Saddler, J.N. 2009. Adsorption of Cellulase on Cellulolytic Enzyme Lignin from Lodgepole Pine. J. Agric. Food Chem. 57(17), 7771-7778.

Uçkun Kiran, E., Trzcinski, A.P., Ng, W.J., Liu, Y. 2014. Bioconyersion of food waste to energy: A review. Fuel, 134(0), 389-399.

Ulbricht, R.J., Northup, S.J., Thomas, J.A. 1984. A review of 5-hydroxymethylfurfural (HMF) in parenteral solutions. Fund. Appl. Toxicol. 4(5), 843-853.

Verduyn, C., Postma, E., Scheffers, W.A., Van Dijken, J.P. 1992. Effect of benzoic acid on metabolic fluxes in yeasts: A continuous-culture study on the regulation of respiration and alcoholic fermentation. Yeast, 8(7), 501-517.

Ververis, C., Georghiou, K., Christodoulakis, N., Santas, P., Santas, R. 2004. Fiber dimensions, lignin and cellulose content of various plant materials and their suitability for paper production. Ind. Crop. Prod. 19(3), 245-254.

Vicuña, R. 2000. Ligninolysis. Mol. Biotechnol. 14(2), 173-176.

Viegas, C.A., Sá-Correia, I. 1991. Activation of plasma membrane ATPase of Saccharomyces cerevisiae by octanoic acid. J. Gen. Microbiol. 137(3), 645-651.

Vivekanand, V., Olsen, E. F., Eijsink, V. G., \& Horn, S. J. (2014). Methane Potential and Enzymatic Saccharification of Steam-exploded Bagasse. BioRes., 9(1), 1311-1324.

Wang, N., Zhang, J., Wang, H., Li, Q., Wei, S.a., Wang, D. 2014. Effects of metal ions on the hydrolysis of bamboo biomass in 1-butyl-3-methylimidazolium chloride with dilute acid as catalyst. Bioresour. Technol. 173(0), 399-405.

Ximenes, E., Kim, Y., Mosier, N., Dien, B., Ladisch, M. 2010. Inhibition of cellulases by phenols. Enzyme Microb. Technol. 46(3-4), 170-176.

Ye, Z., Berson, R.E. 2014. Factors affecting cellulose hydrolysis based on inactivation of adsorbed enzymes. Bioresour. Technol. 167(0), 582-586. 
Yin, J., Wang, K., Yang, Y., Shen, D., Wang, M., Mo, H. 2014. Improving production of volatile fatty acids from food waste fermentation by hydrothermal pretreatment. Bioresour. Technol. 171(0), 323-329.

Yoo, J., Alavi, S., Vadlani, P., Amanor-Boadu, V. 2011. Thermo-mechanical extrusion pretreatment for conversion of soybean hulls to fermentable sugars. Bioresour. Technol. 102(16), 7583-7590.

Yuan, T.-Q., You, T.-T., Wang, W., Xu, F., Sun, R.-C. 2013. Synergistic benefits of ionic liquid and alkaline pretreatments of poplar wood. Part 2: Characterization of lignin and hemicelluloses. Bioresour. Technol. 136(0), 345-350.

Yücel, H. G., \& Aksu, Z. (2015). Ethanol fermentation characteristics of Pichia stipitis yeast from sugar beet pulp hydrolysate: Use of new detoxification methods. Fuel, 158, 793799.

Zakaria, M.R., Norrrahim, M.N.F., Hirata, S., Hassan, M.A. 2015. Hydrothermal and wet disk milling pretreatment for high conversion of biosugars from oil palm mesocarp fiber. Bioresour. Technol. 181(0), 263-269.

Zhang, Q., He, J., Tian, M., Mao, Z., Tang, L., Zhang, J., Zhang, H. 2011. Enhancement of methane production from cassava residues by biological pretreatment using a constructed microbial consortium. Bioresour. Technol. 102(19), 8899-8906.

Zhao, C., Ding, W., Chen, F., Cheng, C., Shao, Q. 2014. Effects of compositional changes of AFEX-treated and H-AFEX-treated corn stover on enzymatic digestibility. Bioresour. Technol. 155(0), 34-40.

Zhou, X., Ma, J., Ji, Z., Zhang, X., Ramaswamy, S., Xu, F., Sun, R.-c. 2014. Dilute acid pretreatment differentially affects the compositional and architectural features of Pinus bungeana Zucc. compression and opposite wood tracheid walls. Ind. Crop. Prod. 62(0), 196-203. 


\section{Figure Captions}

Figure 1: Classification of pre-treatments strategy for lignocellulosic biomass

Figure 2: Enzymatic glucan conversion (left column) and glucose concentration (right column) of organosolvpretreated wheat straw. Source: Adopted from Chen et al. (2015) with permission.

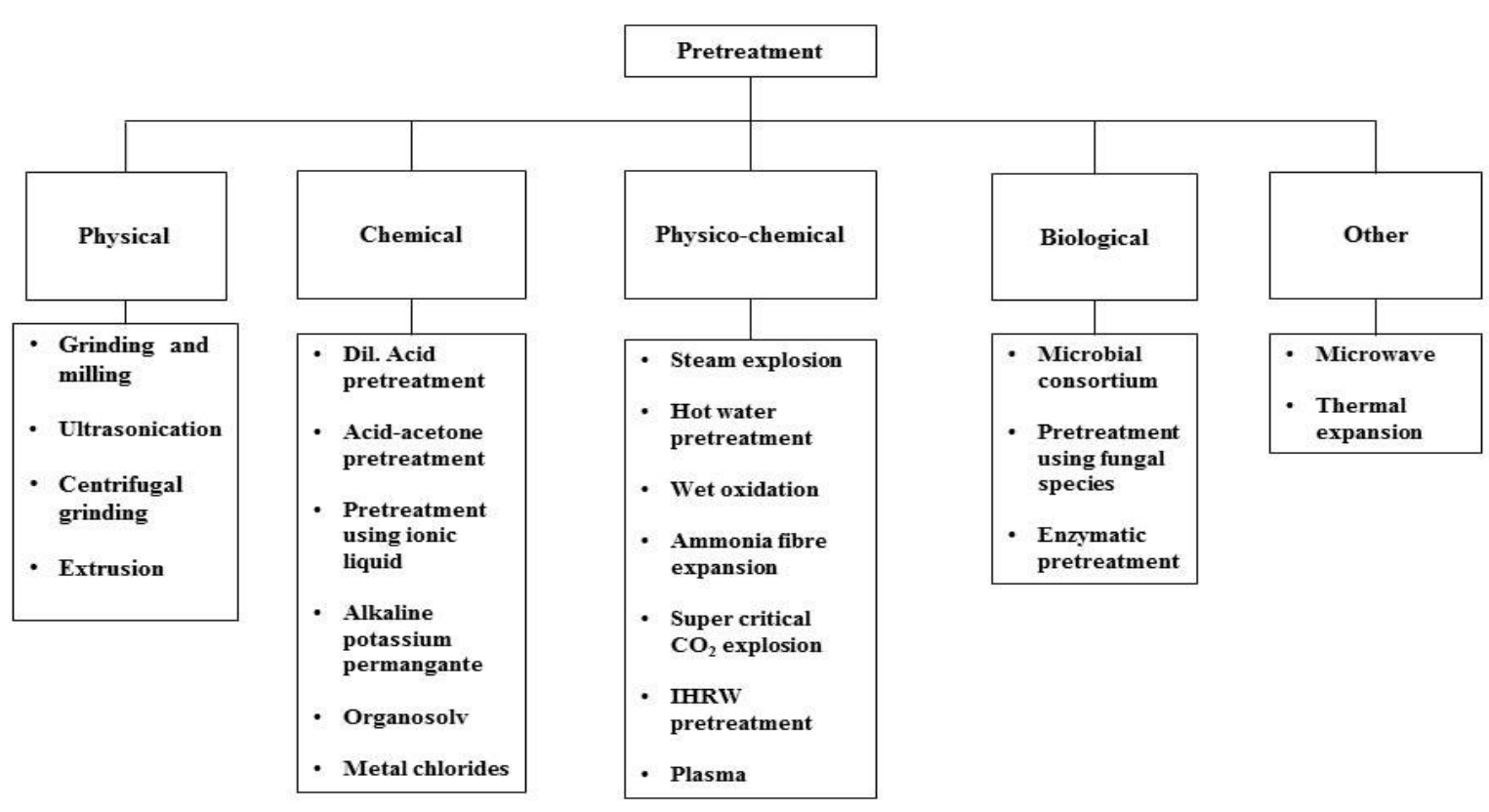

Tigure 1: Classification of pre-treatments strategy for lignocellulosic biomass 

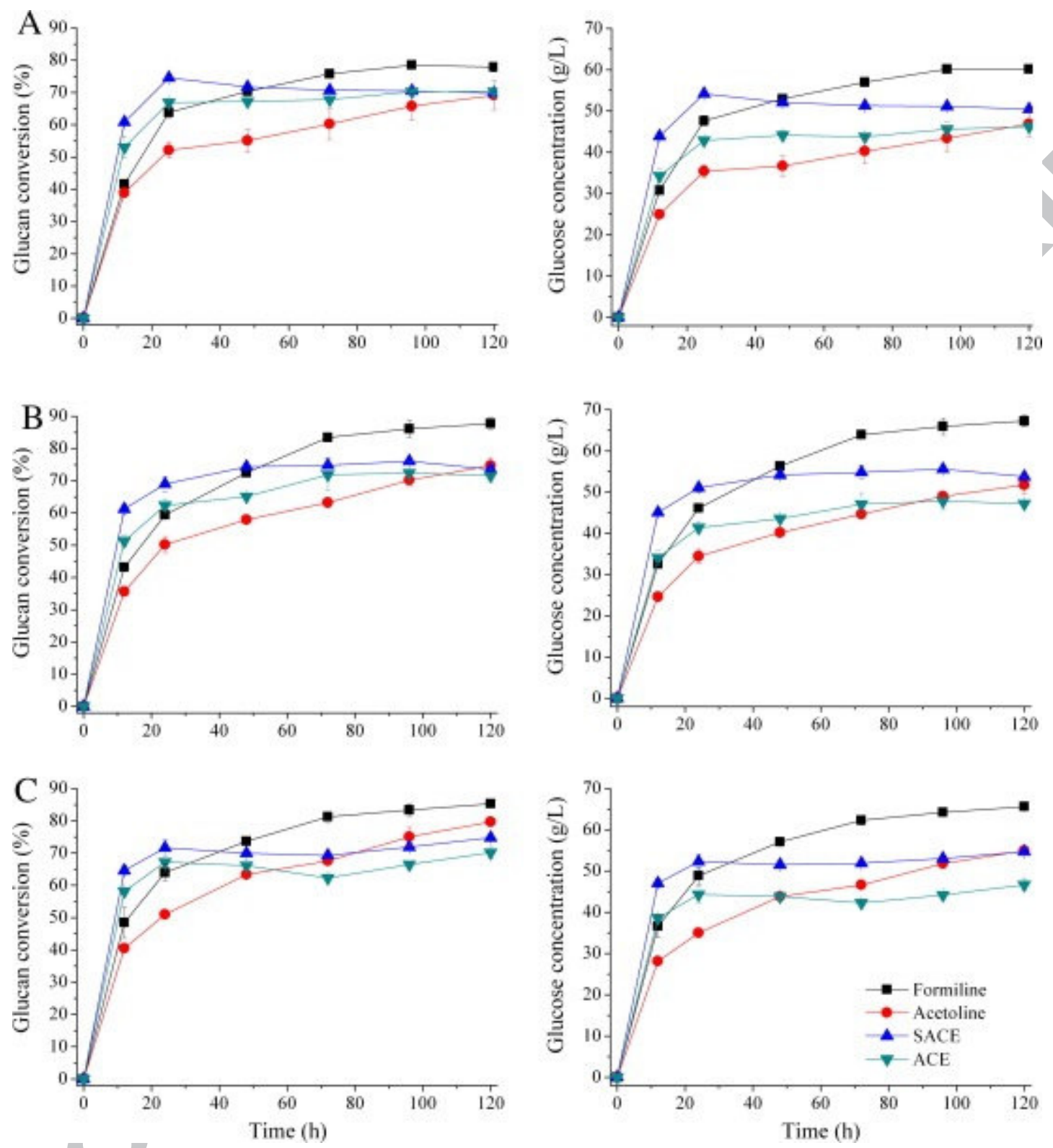

Figure 2: Enzymatic glucan conversion (left column) and glucose concentration (right column) of organosolvpretreated wheat straw.Source: Adopted from Chen et al. (2015) with permission.

Table 1: Comparison of lignocellulosic materials and their pre-treatment strategies

\begin{tabular}{|l|l|l|l|l|}
\hline Pre-treatment & $\begin{array}{l}\text { Lignocellulosic } \\
\text { substrate }\end{array}$ & Composition & & Mode of action \\
\hline
\end{tabular}




\begin{tabular}{|c|c|c|c|c|}
\hline Mechanical & Cotton seed hairs & $\begin{array}{l}\text { Cellulose: } \\
\text { Hemicelluloses: } \\
\text { Lignin: }\end{array}$ & $\begin{array}{c}80-95 \% \\
5-20 \% \\
0 \%\end{array}$ & $\begin{array}{l}\text { - Reduction of particle size associated } \\
\text { with increase of external surface } \\
\text { area }\end{array}$ \\
\hline Alkaline hot water & $\begin{array}{l}\text { Coastal bermuda } \\
\text { grass }\end{array}$ & $\begin{array}{l}\text { Cellulose: } \\
\text { Hemicelluloses: } \\
\text { Lignin: }\end{array}$ & $\begin{array}{c}25 \% \\
35.7 \% \\
6.4 \%\end{array}$ & $\begin{array}{l}\text { - Preserving most of the cellulose } \\
\text { - Significant removal of } \\
\text { hemicelluloses } \\
\text { - Partial depolymerisation of lignin } \\
\text { - Increase in pore size of plant } \\
\text { material }\end{array}$ \\
\hline $\begin{array}{l}\text { Dilute acid pre- } \\
\text { treatment }\end{array}$ & Corn cob & $\begin{array}{l}\text { Cellulose: } \\
\text { Hemicellulose: } \\
\text { Lignin: }\end{array}$ & $\begin{array}{l}45 \% \\
35 \% \\
15 \%\end{array}$ & $\begin{array}{l}\text { - Nearly complete removal of } \\
\text { hemicelluloses } \\
\text { - Significant disruption and } \\
\text { redistribution of lignin } \\
\text { - Increase of the plant cell wall pore } \\
\text { size/volume }\end{array}$ \\
\hline $\begin{array}{l}\mathrm{SO}_{2} \text {-catalysed } \\
\text { steam explosion }\end{array}$ & Wheat straw & $\begin{array}{l}\text { Cellulose: } \\
\text { Hemicellulose: } \\
\text { Lignin: }\end{array}$ & $\begin{array}{l}30 \% \\
50 \% \\
15 \%\end{array}$ & $\begin{array}{l}\text { - Reduction of particle size associated } \\
\text { with increase in specific surface area } \\
\text { - Significant removal of } \\
\text { lignocellulose } \\
\text { - Partial transformation of lignin } \\
\text { - Significant expansion in pore size } \\
\text { and volume }\end{array}$ \\
\hline Alkali & Softwood & $\begin{array}{l}\text { Cellulose: } \\
\text { Hemicellulose: } \\
\text { Lignin: }\end{array}$ & $\begin{array}{l}45-50 \% \\
25-35 \% \\
25-35 \%\end{array}$ & $\begin{array}{l}\text { - Significant removal of lignin } \\
\text { - Significant removal of acetyl groups } \\
\text { and uronic acid substitutions on } \\
\text { hemicelluloses } \\
\text { - Swelling of cellulose leading to an } \\
\text { increase of internal surface area }\end{array}$ \\
\hline AFEX & Hardwood & $\begin{array}{l}\text { Cellulose: } \\
\text { Hemicellulose: } \\
\text { Lignin: }\end{array}$ & $\begin{array}{l}40-55 \% \\
24-40 \% \\
18-25 \%\end{array}$ & $\begin{array}{lrr}\text { - Ammonolysis } & \text { of } & \text { lignin- } \\
\text { carbohydrate } & \text { complex } & \text { ester } \\
\text { linkages, solubilisation } & \text { and } \\
\text { relocation of } & \text { cellwall, formation of } \\
\text { nanoporous, } & \text { interconnected } \\
\text { networks } & & \\
\end{array}$ \\
\hline Organosolv & Nut shells & $\begin{array}{l}\text { Cellulose: } \\
\text { Hemicellulose: } \\
\text { Lignin: }\end{array}$ & $\begin{array}{l}25-30 \% \\
25-30 \% \\
30-40 \%\end{array}$ & $\begin{array}{l}\text { - Significant removal of lignin and } \\
\text { hemicelluloses } \\
\text { - Increase of accessible surface area } \\
\text { and pore volume }\end{array}$ \\
\hline Ionic liquid & Switch grass & & & $\begin{array}{l}\text { - Regeneration of amorphous } \\
\text { cellulose } \\
\text { - Disruption of hydrogen bonds } \\
\text { increasing access of cellulase to } \\
\text { cellulose }\end{array}$ \\
\hline
\end{tabular}

Source: Sun \& Cheng (2002)and Meng and Ragauskas (2014) 


\section{Highlights}

- Factors influencing the effective valorization of lignocellulose.

- Classification of pretreatments with detailed description of various strategies.

- Physical, Chemical, Biological and Physico-chemical pretreatment of lignocellulose.

- Formation of inhibitory compounds post pre-treatment of lignocellulose.

- Strategies for effective removal of inhibitory compounds. 


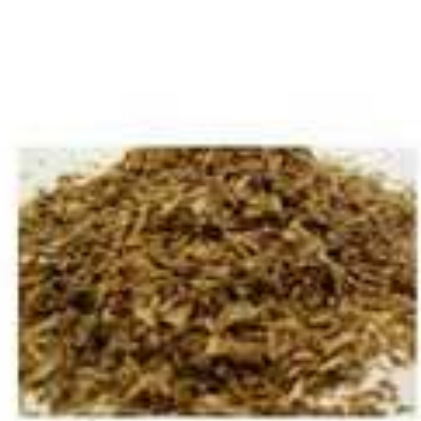

Lignocellulose

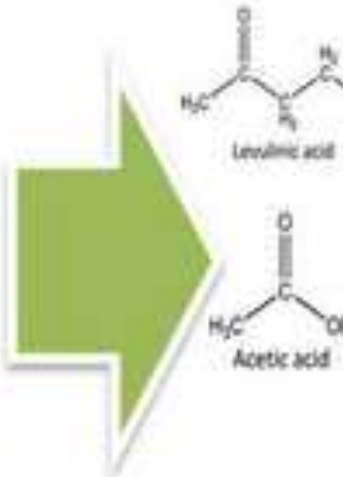

Pre-treatment

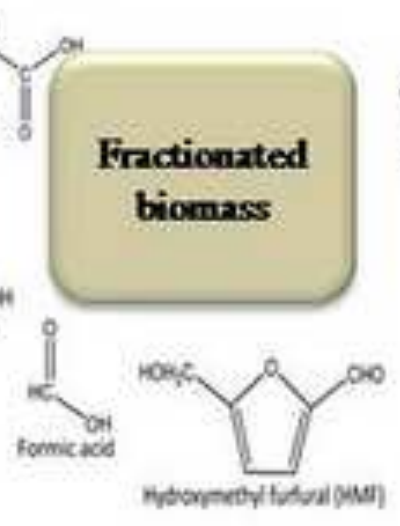

Inhibitor formation
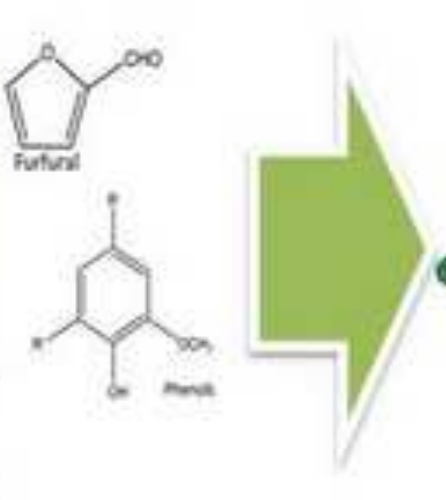

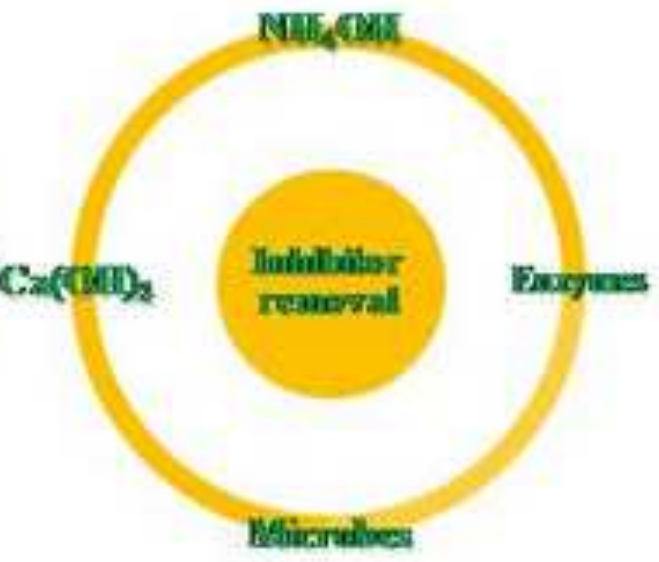

Enzymatic bydrolysis
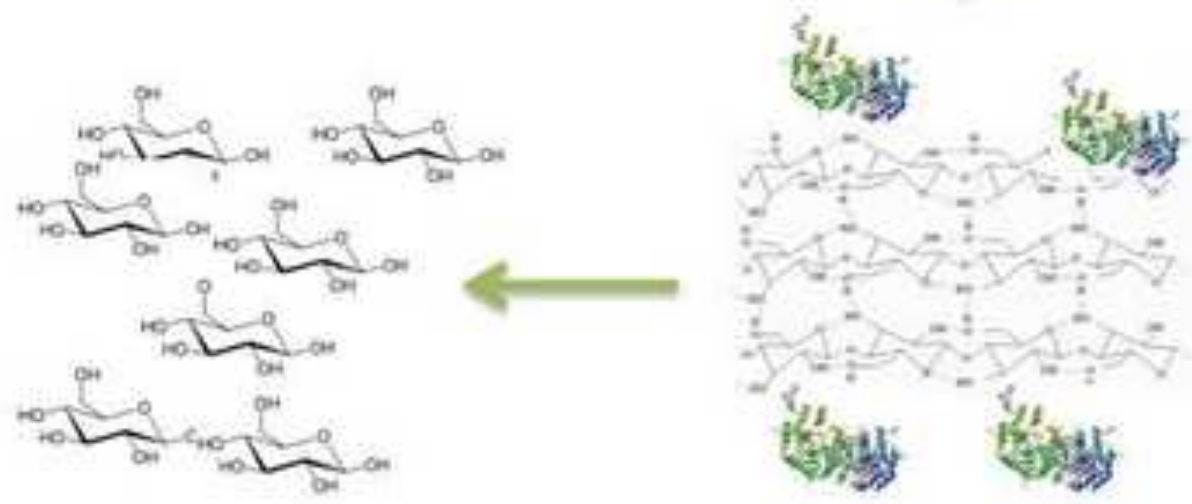

Rectncing

soger

formation 